\title{
The China-Mongolia-Russia economic corridor and Mongolia's energy sector
}

\author{
Batkhuyag Sodovyn ${ }^{1}$, and Boris Saneev ${ }^{2, *}$ \\ ${ }^{1}$ Energy Institute at the Mongolian State University of Science and Technology, Mongolia \\ ${ }^{2}$ Melentiev Energy Systems Institute of Siberian Branch of the Russian Academy of Sciences, Irkutsk, \\ Russia
}

\begin{abstract}
The paper examines the existing and expected energy ties among the People's Republic of China, Mongolia and Russia in terms of the development of Mongolia's energy sector and the country itself, and in light of the cooperation among the three countries. Consideration is also given to the basic conditions that are a good prerequisite for this cooperation, such as large reserves of power-generating fuel and geographical location of these countries. Keywords: Energy sector; neighbouring countries; energy reserves; energy cooperation.
\end{abstract}

Currently, the total installed capacity of Mongolia is very modest. Despite the huge coal reserves and a small population, the power system of the Central region, which provides more than 70 percent of the country's electricity supply, has a significant shortage of peak capacities and very specific generator's structure. The Central Power Grid didn't have any traditional thermal power plant, but only cogenerators, i.e. designed specifically to produce heat and power, in that particular sequence of the output importance. Construction and commissioning of new capacities could both eliminate shortage of peak generators and improve the structure of the power grid. However, the lack of domestic financing sources is the main factor that does not allowing to solve this issue. Given this fact, several years ago the Parliament of Mongolia passed the law "On concessions" and the government of Mongolia authorized some private companies to build power plants under the principle "Build-Operate-Transfer (BOT)". The permit was issued for the construction of a power plant with a total installed capacity of almost $10,000 \mathrm{MW}$, which would be enough to meet the electricity demand of Mongolia for the next ten or twenty years. Unfortunately, not any power plant has been built.

The main reason for such a situation is low tariff and a small power market in Mongolia. While the of domestic market can hardly be expected, as well as electricity price growth will stay at prohibitively low level, the option for new power plant construction under concession agreement is absent. Under such circumstances one of the main option is seek for cooperation with our two great neighbors (Russia and China); and first of all, actively participate in the "One Belt, One Road" international cooperation program.

\footnotetext{
* Corresponding author: saneev@isem.irk.ru
} 
Four years ago, the PRC leadership announced the launch of the "One Belt, One Road" regional cooperation program (Silk Road Economic Belt and $21^{\text {st }}$ Century Maritime Silk Road). An international forum dedicated to the program of regional cooperation "One Belt, One Way" was held in Beijing on May 14-15, 2018.

Within this two-day conference, Chinese authorities had been organised a series of events dedicated to this program. The event drew some 1500 delegations from 130 countries and 70 international organisations, transforming regional event into international initiative. The President of the People's Republic of China, Mr. Xi Jinping, said: 'At present, more than 100 countries and international organisations have expressed their support to this initiative. Cooperation agreements have been concluded with more than 40 countries, Chinese companies have invested \$ 50 billion in the "One Belt, One Road" Initiative. More than 20 countries located along this Belt collected \$1.1 billion in tax and created over 180 thousand new jobs'.

Construction of a new railway and gradual improvement of the already existing Transsiberian Railroad in the Northeast of Russia are included in the plan to establish economic corridor PRC-Mongolia-Russia. The agreement to create this economic corridor was signed by the leaders of the three countries in June 2016 in Tashkent, at the time of the Shanghai Cooperation Organisation summit.

Thus, it would be unforgivable for Mongolia, as a country involved in the "One Belt, One Road" economic corridor, as a country located close to the largest and fastest growing economy in the world, and as a country rich in coal resources not to take advantage of these good opportunities. Moreover, facing huge environmental and transportation issues, China is seeking chances to import electricity from neighbouring countries. Mongolia's coal reserves are estimated at more than 150 billion tons, while explored and approved reserves exceeding 20 billion tons. This is resources of huge magnitude for Mongolia, whose population is only three million people. Relying on these coal reserves, Mongolia could export power to the PRC, measured by hundreds of TWh annually. It may be worth to mention that in 2016 total electricity consumption in Mongolia was little over 6 billion kWh.

Currently, negotiations are under way to build a large power plant with a total installed capacity of $4800 \mathrm{MW}$ at one of the largest brown coal fields in the south of Mongolia. At first, one power plant with a total installed capacity $3600 \mathrm{MW}$ (six units by $600 \mathrm{MW}$ each) should be build. The power plant will produce more than 23 TWh per year, including 4 to 5 TWh for domestic consumption. This will allows us to fully meet our future needs for the next 10 years, while remaining power generated will be delivered to China. Mongolia will decide how to build and operate this power plant through negotiations with the Chinese side. There can be two options. According to the first one, the Chinese side will provide Mongolia with a loan to purchase equipment and materials, and Mongolia builds the plant and exports the agreed amount of electricity. Under the second option, the Chinese side builds power plant, operates it for 20-25 years, meets the aforementioned demand for electricity and power in Mongolia, and transmits the rest of electricity to China.

At the same time, it is necessary to consider the issues related to the environment and lack of water in the Gobi desert region of Mongolia. First, the dry cooling tower should be build. Second, the waste-free technology should be utilised. The latter includes the ash removal with subsequent storage in ash dumps, combined with subsequent ash utilisation in cement production and road construction. Certainly, the innovative Chinese ultra-clean technologies should be applied to minimise harmful gases and ash emissions.

After the completion of concession the Chinese side provide full renovation and transfers the power plant to the Mongolian side. The Mongolian side builds an appropriate coal open-pit, operates it and provide reliable coal supply to this power plant. As the 
Mongolian power demand grows, we can consider an option for construction of the second similar power plant with the Chinese loan for the equipment and materials delivery. In this case, the construction and machinery installation will be provided by Mongolian qualified staff with the help of Chinese experts invited for a short time from the equipment manufacturing plants.

Guided by the officially declared foreign economic policy of Mongolia to maintain both economic and political cooperation with our two neighbors, along with strengthening energy cooperation with China, we should consider energy cooperation with our northern neighbor. At present, some Russian companies are proposing to strengthen the existing high-voltage transmission line between the power systems of the two sides and to import a sufficient amount of electricity and power at a reasonable price. We should carefully study this proposal bearing in mind the creation of a peak power source to ensure the independent operation of the Central Electric System of Mongolia. During the past few years, our countries have been negotiating the construction of a small (250-300 MW) hydro power plant on the Selenga River. Since there are no any peak generators within the Central Energy Grid (CES) of Mongolia, this hydro power plant is a very important and necessary power source in the CES. Selenga River is a major tributary of Lake Baikal, the World Natural Heritage site, and we should not make any decision on the construction of the hydropower plant until the results of the assessment of its environmental impacts and social consequences are obtained. We are trying to work out all the alternative options that suit both parties. In our opinion, one of the acceptable options would be the construction of a Pumped Storage Power Plant (PSPP). In this case, PSPP has several advantages compared to the classic HPP. Firstly, it will not cause an objection from the Russian side, since it will not have any effect on the water level of Lake Baikal. The lower basin of this PSPP will require only 15-20 million $\mathrm{m}^{3}$ of water. Secondly, the PSPP will cost much less and it will take almost two times less time to construct it than a typical hydro power plant of similar capacity. Almost 80 percent of the capital investment and a long period of time are necessary to construct a huge reservoir to ensure uninterrupted operation of the hydropower plant, and a long and high dam to create water pressure. The pumped storage power plant requires neither a huge lake nor a dam. Therefore, the construction period of the PSPP is shorter compared to the classic hydro power plant and its capital investment is lower. At the same time, PSPP has two-sided regulation: during the evening maximum load it operates as a highly manoeuvrable power source, after the peak load it turned out to consumer, receiving from the power grid. This PSPP characteristic is very important for the Mongolian Central Power Grid. With such a solution for the controversial issue, we will be able to appeal to the Russian side to consider the possibility of granting a soft loan for survey and design, feasibility study, engineering and construction of the above-mentioned PSPP. At the same time, the issue of high capacity, high-voltage transmission lines construction within Mongolia to strengthen power interconnection among PRC, Mongolia and Russia, and later among the NEA countries remains open.

\section{Conclusions}

1. Due to cheap electricity in the domestic market of Mongolia, on the one hand, and a small capacity of the electricity market itself, on the other hand, Mongolia is not attractive for foreign investors in the construction of large power plants under a concession agreement.

2. There is no internal financial source for a large power plant construction. This problem can be solved by supporting the Chinese "One Belt, One Road" initiative and making an agreement with the government of the PRC on a loan for the delivery of 
equipment and materials to construct one large condensing power plant with six $600 \mathrm{MW}$ units and export obligations for up to $20 \mathrm{TWh}$.

3. We must carefully study the Russian proposal related to strengthening the existing tie line between our power systems and importing sufficient amount of electric energy and power at an affordable price, while bearing in mind the development of peak generators.

4. The construction of a PSPP, instead of a classic HPP can be a way out to avoid confrontations related to the impact on the Lake Baikal, the World's Natural Heritage site.

5. The complex framework for Mongolia's energy supply infrastructure development became strong driver to improve multilateral cooperation within conceptual proposals to establish the China-Mongolia-Russia economic corridor.

\section{Acknowledgements}

The research was done with the support of the RFBR, Grant No 18-510-94006.

\section{References:}

1. S. Batkhuyag. Some theoretical, methodological and practical issues of Mongolia's energy development strategy. Monograph (in Mongolian). Ulan Bator, Mongolia, 361 p. (2009)

2. S. Batkhuyag. Briefly about the creation of the Mongolian energy sector and the main stages of its development. The current state and the prospect for further development. Collected papers of the scientific conference "The Directions of Mongolia's Energy Development" dedicated to the 95th anniversary of the Energy Sector of Mongolia (in Mongolian language). Ulan Bator, Mongolia, 398 p. (pp. 112-116) (June 2017)

3. Compiled by Evgeny Simonov. The Silk Road and the ecological civilization of China and its neighbors. Reader, Moscow, 154 p. (2016)

4. Voropai N.I., Saneev B.G., Batkhuyag S., H. Enkhjargal. Energy cooperation of Mongolia and Russia: current status and strategic directions. Spatial economics. Khabarovsk, 2013. 108-122, DOI 10.14530/se.2013.3.108-122

5. N.I. Voropai, B.G. Saneev, I.Yu. Ivanova, A.D. Sokolov, E.P. Maisyuk, N.M. Sysoeva, G.O. Borisov, S. Batkhuyag, H. Enkhjargal. Forecasting strategic directions of energy cooperation between Russia and Mongolia. Scientific cooperation of the Siberian branch of RAS with Mongolia in the first half of the 21st century. Issue 1: 2011-2013Novosibirsk: SB RAS Publishing, 2015. - 275 p.

6. Saneev B.G. The priority directions of energy cooperation of the countries in the framework of the economic corridor "China-Mongolia-Russia": the role of the fuel and energy potential of the Baikal region. Collected papers of the scientific conference "China-Mongolia-Russia economic corridor: road map", III ${ }^{\text {rd }}$ International Forum of the China, Mongolia and Russia Expert Centers Association" // editors B.V. Bazarov, Yang Changhua. - Ulan-Ude: Publishing house BNC SB RAS, 2017. - 324 p. (p. 100104).)

7. Saneev B., Ivanova I., Izbuldin A., Muzychuk S., Maysyuk E., Borisov G., Butkhuyag S. The Russian-Mongolian Vector of the Eastern Energy Strategy of Russia: Role of Energy Potential of the Baikal Region // E3S Web of Conferences 2018. 10th International Conference on Asian Energy Cooperation, AEC 2017 Irkutsk, 29-31 August 2017 г. T.27, DOI: 10.1051/e3sconf/20182702006 